\title{
Complex organic matter in Titan's aerosols?
}

\author{
Arising from: G. Israël et al. Nature 438, 796-799 (2005)
}

On 14 January 2005, the Huygens probe entered the atmosphere of Titan after a sevenyear interplanetary flight as part of the Cassini mission to Saturn. Huygens carried, among other instruments, an aerosol collection and pyrolysis (ACP) device ${ }^{1}$. Its designers, Israël et al. ${ }^{2}$, now claim to have detected complex organic matter in two aerosol samples collected at different altitudes $(130-35 \mathrm{~km}$ and 25-20 km, respectively), on the basis of their detection of ammonia $\left(\mathrm{NH}_{3}\right)$ and hydrogen cyanide ( $\mathrm{HCN})$ when the sample oven was heated to $600{ }^{\circ} \mathrm{C}$. However, the authors' remarkable conclusions, which would have far-reaching consequences for our understanding of the chemical environment prevailing on Saturn's largest moon, are not supported by their limited data.

The claim by Israël et al. ${ }^{2}$ to have detected $\mathrm{NH}_{3}$ is based on the signal they obtain at a mass-to-charge ratio $(\mathrm{m} / \mathrm{z})$ of 17 in the 18 mass spectra (see their Fig. 3) recorded for sample 2 after the sample oven had been heated to $600{ }^{\circ} \mathrm{C}$ and swept with an isotope of nitrogen $\left({ }^{15} \mathrm{~N}_{2}\right)$. However, with a single exception (at 10:57:27), these signals can be accounted for by methane containing ${ }^{13} \mathrm{C}$ (that is, ${ }^{13} \mathrm{CH}_{4}$ ), as calculation from the signal at $m / z 16\left({ }^{12} \mathrm{CH}_{4}\right)$ and the ${ }^{12} \mathrm{C} /{ }^{13} \mathrm{C}$ ratio (82.3) of Titan's atmospheric methane indicates ${ }^{3}$; sample 1 apparently produced similar results ${ }^{2}$. Considering the small signals and large error bars indicated in Fig. 3 of ref. 2, it is not valid to conclude that ammonia has been detected in these experiments.

The claim by Israël et al. ${ }^{2}$ that HCN could be detected is also unsupported by their data. The signal for $m / z 27$ in the mass spectrum for sample 1 is the same as that from the background (their Fig. 1) and, as the authors point out, the small peak in the spectrum for sample 2 (their Fig. 2) may well be a fragment of ethane or ethylene. The signals above $\mathrm{m} / z 27$ of these known constituents of Titan's atmosphere are obliterated by those from the large amounts of light $(\mathrm{m} / z 28,29)$ and heavy nitrogen $(\mathrm{m} / z 30)$.

These two spectra are dominated by signals at $m / z 16,28$ and 40, which correspond to the components of the atmosphere $\left(\mathrm{CH}_{4},{ }^{14} \mathrm{~N}_{2}\right.$ and $\left.{ }^{40} \mathrm{Ar}\right)$. This may have entered the sample cavity through the leaking gaskets, which had caused the loss of all data from the "ambient" and $250{ }^{\circ} \mathrm{C}$ experiments ${ }^{2}$ (see section 2 and Fig. 4 of the supplementary information accompanying ref. 2). These leaks would also explain the increase in the signals for sample 2, because it was collected at lower altitude (higher pressure). There is therefore no compelling evidence that any aerosol was collected or that anything was pyrolysed in these experiments.

What the authors mean by the "complex organic matter" they claim to have detected in Titan's atmospheric aerosols is illustrated in their supplementary Fig. 6: a remarkable, detailed structure, consisting of an aromatic and a cyclohexane ring, connected and substituted by several linear and branched aliphatic chains, bearing one amino, two imino and two nitrile groups. Even though this is designated as a "probable" structure, it is not justified on the basis of the authors' dubious evidence for the presence of $\mathrm{NH}_{3}$ and $\mathrm{HCN}$.

Compounds of this type would pyrolyse to small unsaturated aliphatic and aromatic molecules. Benzene and its homologues are easy to detect by mass spectrometry at very low levels owing to their aromaticity. They give rise to abundant molecular ions at $m / z 78$ and $78+14 n$, respectively, which is well within the mass range $(m / z 2-142)$ of the mass spectrometer aboard the Huygens probe ${ }^{3}$. To explain their absence, Israël et al. suggest that the spectrometer has low sensitivity above $\mathrm{m} / z 50$.

To justify the extrapolation from $\mathrm{NH}_{3}$ and $\mathrm{HCN}$ to complex organic matter of the type shown in their supplementary Fig. 6, Israël et al. ${ }^{2}$ rely on laboratory analogues (tholins) of Titan's aerosols. These have been produced in various laboratories ever since data from Voyager's 1980 fly-by of Titan showed that its atmosphere consists of nitrogen and a few per cent of methane. Irradiation of such mixtures with various energy sources invariably produced some amorphous materials ${ }^{1,4-6}$, but these were only crudely characterized and not even partially separated for structural analysis. In support of their assertion that such a tholin on pyrolysis produces only $\mathrm{NH}_{3}$ and HCN (but nothing else), the authors show a gas chromatogram in their supplementary Fig. 1 . However, that figure shows only the region from about 2-10 min of the 60-min chromatogram, cutting off just after the emergence of $\mathrm{HCN}$ at $9.35 \mathrm{~min}$, beyond which many other pyrolysis products are likely to emerge ${ }^{1,5}$. The claim to have detected complex organic matter in Titan's atmospheric haze is therefore further undermined.

Other data obtained from the successful Cassini-Huygens mission contradict or correct some previously held notions about Titan, its origin and its environment ${ }^{3,7,8}$. The idea that the observed haze must be due to aerosol particles consisting of large organic molecules of complex structure needs to be re-evaluated. The chemical nature of the haze on Titan still remains shrouded in mystery.

\section{K. Biemann}

Department of Chemistry, Massachusetts

Institute of Technology, Cambridge,

Massachusetts 02139, USA

e-mail: kbiemann@mit.edu

\footnotetext{
1. Israël, G. et al. Space Sci. Rev. 104, 435-466 (2002).

2. Israël, G. et al. Nature $438,796-799$ (2005).

3. Niemann, H. et al. Nature 438, 779-784 (2005).

4. Khare, B. N. et al. Adv. Space Res. 4, 59-68 (1984).

5. Coll, P., Coscia, D., Gazeau, M.-C., Guez, L. \& Raulin, F. Orig. Life Evol. Biosph. 28, 195-213 (1997).

6. Somogyu, A., Oh, C.-H., Smith, M. A. \& Lunine, J. I. J. Am Soc. Mass Spectrom. 16, 850-859 (2005).

7. Porco, C. C. et al. Nature 434, 159-168 (2005)

8. Zarnecki, J. C. et al. Nature 438, 792-795 (2005).
}

doi:10.038/nature05417

aerosols to be investigated. Our aerosol collection and pyrolysis (ACP) measurements in Titan's atmosphere can then be revisited.

Biemann doubts that we were detecting $\mathrm{NH}_{3}$ and $\mathrm{HCN}$ after the pyrolysis steps at $600{ }^{\circ} \mathrm{C}$, as well as questioning our deductions. If the detection is valid, our inference is clear. The data obtained from temperature sensors in flight undoubtedly show that the oven heaters did work nominally, so any volatile material collected by ACP along with the haze particles must have been vaporized during the $250{ }^{\circ} \mathrm{C}$
Biemann ${ }^{1}$ calls into question our preliminary interpretations of our experimental results ${ }^{2}$. A comparison of laboratory and flight measurements should settle the uncertainties he raises. In addition to evaluating instrumental characteristics such as the 'piston effect', a technique we used for injecting oven-gas content for gas chromatography-mass spectrometry (GC-MS), such studies should enable a wide range of possible compositions for Titan's 
heating step, and - as indicated by the reading of the oven pressure sensors - evacuated from the ACP-GC-MS. Consequently, only the refractory part of the aerosols could have remained in the oven afterwards. The detection of $\mathrm{NH}_{3}$ and $\mathrm{HCN}$ in the products formed during the pyrolysis of this unknown, but refractory, material indicates that it must comprise a mixture of carbon-, hydrogen- and nitrogencontaining species.

Biemann suggests that the laboratory analogues of Titan's aerosols were only crudely characterized and not even partially separated for structural analysis; however, this is not correct. The laboratory tholins were recovered and studied using different techniques in order to determine their chemical composition and their cracking patterns, which are the parameters required for interpreting observational data ${ }^{3-7}$. $\mathrm{He}$ also misinterprets our comments on the specific structure of the aerosols. Our supplementary Fig. 6 showing the probable structure of Titan's aerosols (ref. 2) is intended to illustrate a representative example of what could be part of the structure of the complex organic material, and not what it actually is. This structure was constructed from the nature of the identified pyrolysates: nitrile groups to produce $\mathrm{HCN}$, and amino or imino groups to produce $\mathrm{NH}_{3}$. This type of illustration has previously been used ${ }^{8}$, based on experimental work'

An important puzzle that will be addressed by laboratory simulations is why there are no fragments of high relative molecular mass in the spectra of the pyrolysate formed at $600{ }^{\circ} \mathrm{C}$, which may be explained by their destruction during transport to the detector. We must, of course, accept the possibility that we could have been misled in our preliminary interpretations by a remarkable set of coincidences, which is why we are now completing a rigorous set of laboratory calibrations before reaching a final judgement on the results of the experiment.

G. Israël', C. Szopa', F. Raulin², M. Cabane', H. B. Niemann ${ }^{3}$, S. K. Atreya ${ }^{4}$, S. J. Bauer ${ }^{5}$, J.-F. Brun' , E. Chassefière' ${ }^{1}$, P. Coll ${ }^{2}$, E. Condé ${ }^{6}$, D. Coscia ${ }^{2}$, A. Hauchecorne', P. Millian?, M. J. Nguyen ${ }^{2}$, T. Owen ${ }^{8}$, W. Riedler ${ }^{9}$, R. E. Samuelson ${ }^{10}$, J.-M. Siguier ${ }^{7}$, M. Steller ${ }^{11}$, R. Sternberg ${ }^{2}$, C. Vidal-Madjar ${ }^{12}$

'Service d'Aéronomie UMR 7620 CNRS, ISPL, Universities Paris 6 and Versailles-Saint Quentin, Verrières-le-Buisson 91371, France

${ }^{2}$ Laboratoire Interuniversitaire des Systèmes Atmosphériques, UMR 7583 CNRS, Universities Paris 12 and Paris 7, Créteil 94010, France ${ }^{3}$ NASA Goddard Space Flight Centre, Greenbelt, Maryland 20771, USA
${ }^{4}$ Department of Atmospheric, Oceanic and Space Sciences, University of Michigan, Ann Arbor, Michigan 48109, USA

${ }^{5}$ Institute for Meteorology and Geophysics, University of Graz, Graz 8010, Austria

${ }^{6}$ Centre National d'Etudes Spatiales (CNES), Toulouse 31401, France

${ }^{7}$ Office National d'Etudes et de Recherches Aérospatiales, Toulouse 31055, France

${ }^{8}$ Institute for Astronomy, University of Hawaii at

Manoa, Honolulu, Hawaii 96822, USA

${ }^{9}$ Space Research Institute, Graz 8010, Austria

${ }^{10}$ Department of Astronomy, University of Maryland, College Park, Maryland 20742, USA

${ }^{11}$ Institut für Weltraumforschung, Österreichische Akademie der Wissenschaften, Graz 8042,

Austria

${ }^{12}$ Laboratoire de Recherche sur les Polymères, UMR 7581 CNRS, Thiais 94320, France

1. Biemann, K. Nature 444, doi:10.1038/nature05417 (2006)

2. Israël, G. et al. Nature 438, 796-799 (2005).

3. Khare, B. N. et al. Icarus 60, 127-137 (1984).

4. McDonald, G. D. et al. Icarus 108, 137-145 (1994).

5. Coll, P. et al. Planet. Space Sci. 47, 1331-1340 (1999)

6. Ramirez, S. I. et al. Icarus 156, 515-529 (2002).

7. Bernard, J. M. et al. Icarus 185, 301-307 (2006).

8. Thompson, W. R., Henry, T. J., Schwartz, J. M., Khare, B. N. \& Sagan, C. Origins of Life 19, 475-476 (1989).

9. Lichtin, D. A. \& Lin, M. C. Chem. Phys. 104, 325-330 (1986).

doi:10.038/nature05418 